\title{
A PÁGINA DA EDUCAÇÃO. UMA PUBLICAÇÃO COM PASSADO, PRESENTE E FUTURO
}

\section{A Página da Educação - A publishing with past, present and futur}

\author{
Isabel BAPTISTA \\ Diretora da revista A Página da Educação \\ Universidade Católica Portuguesa \\ Correo-e: ibaptista@porto.ucp.pt \\ Recibido: 20 de julio de 2020 \\ Envío a informantes: 26 de julio de 2020 \\ Aceptación definitiva: 28 de septiembre de 2020
}

Resumen: A Página da Educação es una publicación portuguesa editada, ininterrumpidamente, desde i99i. Con un amplio apoyo de la comunidad docente y, más en concreto, del Sindicato dos Professores do Norte, constituye uno de los principales referentes en la prensa pedagógica del país, proyectando sus logros en otros contextos y realidades. Con este artículo se pretende enfatizar sus señas de identidad como un proyecto editorial único, poniendo de relieve los momentos más significativos de su trayectoria histórica, vocacionalmente comprometida con la democracia, la educación, la ciencia y la cultura. Un pasado que mira al futuro con la intención ser más rica, relevante y -tanto como sea posible- en acceso abierto.

Palabras Clave: educación; prensa pedagógica; sindicatos de enseñanza; proyecto editorial.

Aвsтract: A Página da Educação is a Portuguese magazine, edited uninterruptedly since 1991. Born within the teaching community, more precisely in the context of a Teachers' Union (Sindicato dos Professores do Norte), but assuming a broader vocation. In favour of democracy, education, science and culture, this publication constitutes an important reference in the pedagogical press, both in the country and abroad. This article aims to highlight the identity traits of this unique editorial project, emphasizing 
the most significant moments in its history. A long, rich, relevant and desirably open history.

KEY WORDS: education; pedagogical press; teachers' union; editorial project.

\section{Introdução}

$\mathrm{E}$

STE artigo surge na sequência da presença da revista portuguesa $A$ Página $d a$ Educação no III Congreso sobre Prensa Pedagógica, promovido pela Faculdade de Educação da Universidade de Salamanca, em outubro de 20I8, cabendo-nos, desde já, agradecer aos seus organizadores a oportunidade de participação num encontro internacional tão pertinente e prestigiado. Uma participação que desejamos prolongar através deste texto, na convicção comum de que importa dar relevo à imprensa pedagógica, enquanto elemento fundamental nos processos de valorização do património histórico educativo.

A Página da Educação ou a PÁGINA, como é comummente designada a nossa publicação, é um órgão de informação vocacionado para a partilha do conhecimento com interesse para o desenvolvimento da sociedade em geral e dos campos da educação, ensino e ciência, em particular. Publicada em Portugal pela Profedições, uma editora ligada ao Sindicato dos Professores do Norte (SPN), a PÁGINA conta já com três décadas de história, constituindo-se hoje como uma referência incontornável no panorama educacional, dentro do país e fora dele.

A PÁGINA é produzida por uma equipa multidisciplinar, composta por docentes de diferentes setores de ensino, jornalistas, fotógrafos e outros profissionais da comunicação e por uma rede de colaboradores permanentes integrada por especialistas com reputação reconhecida, designadamente investigadores e profissionais da educação, oriundos de Portugal, de países europeus como o Reino Unido e Espanha, do Brasil e dos países africanos de língua portuguesa.

Nascida no interior da comunidade docente, a PÁGINA expressa uma visão ampla da educação, com foco nas questões do sistema educativo e da educação escolar, mas também da intervenção socioeducativa. Ao mesmo tempo, e em conformidade com o seu estatuto editorial, procura dar atenção às questões sociais e culturais, abordando temas atuais e de interesse público. De tal maneira que percorrer as páginas da PÁGINA significa revisitar os acontecimentos, as preocupações e as interpelações, que marcaram a história da democracia e da educação nos últimos anos.

$\mathrm{Na}$ tentativa de fazer justiça a uma história particularmente rica e extensa, recorremos, sobretudo, à palavra dos seus protagonistas. Na consciência, porém, dos limites inerentes a um texto, forçosamente subjetivo e incompleto, escrito por alguém ligado à vida da PÁGINA, primeiro como colaboradora e depois, desde há II anos, como diretora. Como recordava Rogério Fernandes (2008, p. 8), um dos maiores nomes da História da Educação em Portugal, não há forma de contornar a distância inevitável que existe entre o tempo medido e o tempo vivido, «entre o tempo em curso e o tempo recordado, o tempo objeto de registo e o tempo que se esvai e não cabe no escrito». 


\section{Três décadas de história - ao serviço da democracia e da educação}

A história da PÁGINA poderá ser dividida em duas etapas fundamentais, uma primeira correspondente à sua publicação como jornal mensário, desde I99I até 2009, e uma segunda referente à sua edição como revista, desde 2009 até à atualidade. O número zero do então jornal $A$ Página da Educação saiu a público a 2I dezembro de I99I e, logo a seguir, em janeiro de I992, chegava oficialmente aos leitores o «número um», cumprindo-se assim um desejo coletivo, protagonizado por José Paulo Serralheiro, o dirigente do SPN que assumiu as funções de diretor e editor até ao fim da sua vida, em 2009.

Após 17 anos de publicação mensal, a PÁGINA entrou num novo ciclo, justificado por constrangimentos circunstanciais de ordem financeira, mas também pela vontade de reinvenção de um projeto que sempre se pretendeu vivo e atuante. Em carta dirigida aos colaboradores, datada de 2I/10/2008, o "Zé Paulo», como carinhosamente era tratado o diretor, apelava à colaboração de todos para a mudança necessária, acreditando que, com imaginação e perseverança, seria possível continuar a dar vida à PÁGINA, que passaria então ao formato de revista, editada no primeiro dia de cada estação do ano.

Infelizmente, a saúde do Zé Paulo não permitiu dar seguimento a essa intenção no tempo desejado, pelo que o primeiro número da revista, correspondendo à edição n. ${ }^{\circ}$ I85, só viria a sair a público no Verão de 2009. A revista seguinte (Outono 2009, n. ${ }^{\circ}$ I86), representou já uma homenagem a José Paulo Serralheiro, falecido, entretanto, mas contanto ainda, em boa parte, com o seu trabalho de edição, numa extraordinária demonstração de entrega pessoal. Conforme sublinhava o «anti-editorial» desse número especial, assinado por Abel Macedo, Coordenador do SPN, a melhor homenagem que poderíamos prestar a um «companheiro de jornada» como o Zé Paulo, e porventura aquela que mais lhe agradaria, seria procurar manter vivo o projeto que tinha abraçado desde sempre e ao qual havia dedicado as suas últimas energias.

A edição de Inverno (2009, n. ${ }^{\circ}$ I87) surge a público com um título de capa bem expressivo dessa vontade, «I8 anos, vamos continuar». No lugar de um diretor, passou a existir uma equipa diretiva, constituída por uma diretora (Isabel Baptista), uma subdiretora (Ana Brito Jorge) e um editor (António Baldaia), mandatados para as respetivas funções pelos Corpos Gerentes do SPN e apoiados por um Conselho Editorial formado por dirigentes sindicais de todos os setores de ensino. Entrava-se, assim, na segunda etapa da história da PÁGINA.

Como foi dito, estamos perante um projeto editorial do Sindicato dos Professores do Norte, sendo por ele subsidiado a título de distribuição gratuita de exemplares a todos os seus associados que, deste modo, asseguram um universo amplo de assinaturas. No entanto, este suporte de base, fundamental para a manutenção e sobrevivência da publicação, nunca constituiu uma ameaça à sua independência e autonomia. $\mathrm{O}$ SPN possui, aliás, um órgão de informação próprio, consistentemente alinhado com a agenda sindical. A missão atribuída à PÁGINA, desde a sua criação, foi de natureza totalmente diferente. Como lembrou Manuela Mendonça (20ı6, p. 153), Coordenadora do SPN, Presidente do Conselho Nacional da Federação Nacional de Professores (FENPROF) e membro do Conselho Executivo da Internacional da Educação (IE), «a Página é ilustrativa do tipo de sindicalismo que perfilhamos - um sindicalismo de espetro amplo, que não dissocia as questões do estatuto laboral das questões do estatuto 
profissional; um sindicalismo sempre na linha da frente, não só da reivindicação, mas também do estudo e do debate que configuram a especificidade da profissão docente».

A PÁGINA é uma publicação subordinada aos «valores de abril», isto é, aos princípios que presidiram à revolução democrática de 25 de abril de 1974, um dia ansiosamente esperado pelos portugueses, descrito de modo sublime pela poetisa Sophia de Mello Breyner (20I5, p. 668) como «o dia inicial inteiro e limpo, onde emergimos da noite e do silêncio e livres habitamos a substância do tempo». O país podia, finalmente, viver a liberdade que lhe fora roubada durante o Estado Novo, o regime autoritário que sucedeu à ditadura militar nascida do golpe de Estado de 28 de maio de 1926 e que vigorou em Portugal durante $4 \mathrm{I}$ anos, desde a aprovação da Constituição de 1933 até esse dia glorioso de 1974 .

Contribuir para que «abril» continue a acontecer, perseverando na promoção de um olhar sensível e cosmopolita, um olhar curioso e aberto ao mundo, é este o grande propósito da PÁGINA, conforme surge patenteado na edição comemorativa dos quarenta anos da «revolução dos cravos» (Primavera 20I4, n. ${ }^{\circ}$ 203). Este número da revista assinala também a sua passagem a edição semestral, deixando assim de estar associada às estações do ano. Uma mudança justificada por constrangimentos de ordem político-financeira que, entre outras medidas, obrigaram à diminuição da equipa de redação. Ou seja, neste aspeto como noutros, a vida da PÁGINA acompanha os tempos da vida da sociedade portuguesa que, nesta altura, eram marcados por grandes dificuldades socioeconómicas.

Gomes Bento, autor de uma obra marcante sobre o movimento sindical dos professores nos finais da monarquia e primeira república portuguesa, e um dos fundadores do SPN, alertava para a forma como, durante a ditadura, a classe docente se vira obrigada a fazer um suicídio de honra, uma espécie de hara-kiri coletivo. Nas suas palavras, «ao desinteresse de si somava-se o esquecimento do seu passado associativo. Esta amnésia coletiva exprime bem a despersonalização absoluta de milhares de homens e mulheres ligados pela mesma profissão, pelos mesmos interesses, pelos mesmos problemas, submetidos à mesma autoridade, mas que desintegrados da solidariedade comum apenas devolvem aos outros a imagem do seu nada» (Bento, 1978, p. II).

Ora, é, justamente, contra o obscurecimento da memória coletiva e numa perspetiva de aprofundamento dos valores da educação e da democracia, que se inscrevem os princípios matriciais da PÁGINA, consagrados no seu estatuto editorial, nomeadamente:

I. A Página da Educação tem como objetivo particular contribuir para a formação integral dos educadores e professores de todos os graus de ensino e dos profissionais da educação social;

2. Favorecer a cooperação entre instituições de investigação, ensino e educação, alunos e professores e demais interessados na produção científica e no seu usufruto, bem como no ensino e educação social;

3. Considerar a liberdade de expressão, a diversidade de ideias, de projetos, de opiniões e de práticas, como elementos estruturantes de uma sociedade democrática.

Estas preocupações encontram-se traduzidas na pluralidade e variedade de rúbricas, assinadas por autores provenientes das mais diversas áreas de saber, bem como 
nas entrevistas e reportagens que compõem cada edição. Ao longo dos anos, a PÁGINA tem tentado, por um lado, dar conta das novidades e, por outro, aprofundar temas que constituem autênticos dossiês de referência, como nota João Teixeira Lopes, um conhecido sociólogo português e colaborador permanente. «Em certa medida, no fio das várias edições, vislumbra-se um horizonte de utopia, não como algo de intangível e etéreo, mas enquanto dimensão palpável, realista e gradativa que, passo a passo, edição após edição, na acumulação da troca de saberes, nos entusiasma e une, apesar das salutares diferenças de perspetiva» (2017, edição n. ${ }^{209}$, p. 7).

Visando potenciar os espaços de partilha e debate, por incitativa própria, ou em colaboração com outras entidades, a PÁGINA tem vindo a organizar diversos eventos, seminários e debates, marcando assim presença regular no espaço público da educação. Neste contexto, na entrada de 20ıo, ano em que Portugal celebrava o centenário

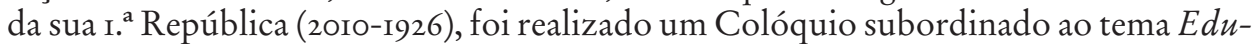
cação e Res Pública (Porto, 2 de outubro), que, entre outros intervenientes ilustres, contou com a participação de José Hernández Díaz, nosso colaborador permanente e catedrático de Teoria e História da Educação da Universidade de Salamanca. Alertando para a importância do ideal republicano, o autor lembrou que o republicanismo representa, sobretudo, uma aspiração permanente em torno da capacitação democrática das sociedades e dos indivíduos. «Por ello resulta tan decisivo y central en qualquer proyeto republicano el pensamiento libre, la razón, la libertad, la Educación como instrumento de conquisa de libertad» (20I0, edição n. ${ }^{\circ}$ I9I). De notar aqui o uso da grafia original, segundo o critério da revista de publicar nas variantes do Português, Mirandês, Galego e Castelhano, sempre em respeito pela opção dos autores.

A par da sua edição em papel, tão valorizada pelos leitores, a PÁGINA desenvolve um processo de edição permanente na Internet (www.apagina.pt), pretendendo, por um lado, assegurar uma ligação mais estreita e interativa com o seu público, e, por outro, criar um espaço de acolhimento para muitos dos textos que, por limitações da edição impressa, não possam ser divulgados na revista.

No entendimento de que os intelectuais só poderão efetivar o seu poder de inscrição pública se puderem contar com a existência de espaços de escrita capazes de acolher o seu contributo, em 2oII, foi lançada a coleção de livros a Página, chancelada pela Profedições. Quisemos, deste modo, dar aos autores a oportunidade de reunir numa obra única os textos publicados na revista, ajustando-os, para o efeito, às exigências que são próprias da escrita académica. Como tal, as obras da coleção a Página são sujeitas a um processo de arbitragem científica, garantido por investigadores devidamente acreditados, pertencentes ao Conselho Editorial ou à bolsa de colaboradores permanentes.

Assim, ao mesmo tempo que se presta tributo aos autores, cuja colaboração constitui um contributo imprescindível e precioso, prestigia-se também a própria revista, projetando os seus conteúdos para lá do imediato. Os próprios colaboradores valorizam esta dupla perspetiva. David Rodrigues, na apresentação de uma das suas obras publicadas na coleção, afirmava: «Comecei a colaborar com esta revista em 2005 e sempre considerei que estava em boa companhia com o projeto, com os editores e com os seus colaboradores. De certa forma, a edição deste livro é uma homenagem à qualidade, à perseverança e compromisso que A Página da Educação tem assumido no nosso panorama educativo» (Rodrigues, 20I5, p. 9). Na verdade, como lembra, por sua vez, Santos Guerra (20II, p. II), não há outra forma de viver a apaixonante 
questão da cidadania. «No nascemos sabendo ser ciudadanos o ciudadanas, tenemos que aprender a serlo». E o exercício de uma escrita livre, responsável e comprometida, funciona, certamente, como um dos meios privilegiados para essa aprendizagem.

\section{3. $\mathrm{O}$ «futuro presente»}

Recorrendo a uma expressão utilizada por António Nóvoa, em entrevista à PÁGINA (2009, edição n. ${ }^{\circ}$ 187, pp. I4-19), colocamos o futuro da revista nestes termos, como «futuro presente», reconhecendo, com o autor citado, que «a história é o que somos mais o que podemos fazer». Ou seja, procurando manter vivo o seu património histórico, a PÁGINA desenvolve um esforço contínuo de reinvenção e atualização. Como referia o seu primeiro diretor, «queremos uma PÁGINA plural, ponto de convergência de vários modos de ver a educação e a cultura. Não o pluralismo e a diversidade dos liberais que reconhecem o direito de cada um ficar em seu sítio e com a sua razão. Mas o pluralismo e a diversidade que nos obrigam ao confronto de ideias e modos de ver que, arrancando-nos da nossa razão e da nossa verdade, nos ajudam a construir coletivamente outras verdades, outros olhares» (Serralheiro, 20II, p. I2).

Enquanto órgão de informação e opinião, especializado nos campos da ciência, ensino, educação, sociedade e culturas, a PÁGINA pretende manter um vínculo estreito com os investigadores e outros interlocutores das áreas da ciência e da cultura que, enquanto intelectuais críticos, aqui encontram oportunidade para produzir discursos informados, ainda que escritos num formato mais coloquial e interventivo. Citando outro dos nossos autores, trata-se de escrever «crónicas breves, bastante distanciadas de registos académicos, as quais, tendo uma intencionalidade mais cívica ou de intervenção, se constituem, também por isso, como particularmente adversas a posturas supostamente neutras ou politicamente assépticas» (Afonso, 20I2, p. 9).

É importante notar que, graças precisamente a esse registo de escrita breve e menos formal, mas fundamentada, os textos divulgados na PÁGINA funcionam, com muita frequência, como material de suporte às atividades de lecionação, em particular no Ensino Superior, surgindo regularmente citados em investigações científicas enquadradas por cursos de mestrado e doutoramento. Facto que, só por si, confirma a qualidade e a pertinência dos conteúdos da revista, evidenciando um notório reconhecimento junto das comunidades académicas e profissionais. Destacamos a este respeito algumas das opiniões dos colaboradores divulgadas por ocasião do $25 .^{\circ}$ aniversário da PÁGINA (2017, edição n. ${ }^{\circ}$ 209).

É difícil imaginar a educação em Portugal sem a PÁGINa, sem a capacidade de combinar vigor crítico, teoria educacional, capacidade reflexiva. (Licínio Lima, Universidade do Minho)

A tradução no género jornalístico do conhecimento desenvolvido pelas diversas comunidades académicas, assente no primado da leitura e da discussão partilhada, é uma das características que fazem deste projeto algo de único e que há que celebrar. (António Magalhães, Universidade do Porto)

Permito-me testemunhar de perto o valioso contributo que a PÁGINA tem dado, ao longo dos anos para o debate educativo no mundo de língua portuguesa, com significativos reflexos do outro lado do atlântico. (Ivonaldo Leite, Universidade Federal da Paraíba, Brasil) 
La educación en miles de páginas. Eso es, 25 anos después, como passado y futuro, A Página da Educação. Un quehacer cívico, pedagógico y social hecho relato: la razón incómoda y el sentimento inquieto acerca de la educación que tenemos y deseamos. (José António Caride Gomez, Universidade de Santiago de Compostela)

Depois de 25 anos de A Página da Educação no panorama editorial e jornalístico português, podemos ter pelo menos uma certeza - continuamos a precisar da PÁGINA nos próximos 25 anos. (Pascal Paulus, Escola Básica Amélia Vieira Luís, Outurela)

Este tipo de expetativas, verbalizadas pelos colaboradores, mas também pelos leitores, funciona como um mandato exigente, representando um desafio constante para a pequena equipa de redação responsável pelo funcionamento da PÁGINA. Uma equipa comprometida e resiliente, que abraça o projeto com dedicação e afeto, como fizeram questão de declarar os seus elementos principais (20I6, edição n. ${ }^{\circ}$ 208, p. II).

A Página é um projeto que abracei há nove anos. Ainda era jornal mensal e foi interessante acompanhar a passagem a revista e as naturais mudanças. É um projeto que me diz muito e no qual acredito. (Sílvia Enes, secretariado)

Aqui já tive oportunidade de fazer entrevistas marcantes e reportagens sobre projetos que merecem ser valorizados, não só na área da Educação, como nas da Cultura e da Sociedade. É assim um orgulho pertencer à Pagina, um projeto único, aberto ao mundo e aos outros, cujo valor deve ser sempre reconhecido. (Maria João Leite, jornalista)

Num tempo de "pós-verdade», perturbado por múltiplos fenómenos de desinformação, a PÁGINA mantém-se em linha com a sua bússola axiológica, «rejeitando o sensacionalismo, o alarme social, a manipulação da opinião pública, a falsificação do conhecimento e do saber, a confusão ou subordinação da informação a interesses publicitários ou a quaisquer outros interesses comerciais (Estatuto Editorial, 2015). Um compromisso ético pautado por valores de hospitalidade e responsabilidade, equacionados no âmbito de uma racionalidade sensível e atenta à interpelação vinda do rosto de cada ser humano, seja ele quem for (Baptista, 2005, p. 52). Citando palavras do escritor moçambicano Mia Couto, é exatamente isso que nos inspira, «a infinita briga entre sermos um só e sermos plurais e cheios de potencialidades para a alteridade. Esse conflito está presente em cada pessoa, seja ela escritora ou não. Se quisermos, se tirarmos prazer disso, somos todos capazes de surpreender essa multiplicidade de histórias que há em cada um de nós (2013, edição n. ${ }^{\circ}$ 202, p. 48).

A PÁGINA constitui-se como um espaço aberto à opinião dos seus colaboradores, mas também à divulgação da opinião dos seus leitores, perante quem assume a responsabilidade de garantir a qualidade técnica, ética e estética da revista. $\mathrm{Na}$ verdade, as preocupações com a qualidade gráfica representam uma das marcas identitárias e diferenciadoras da nossa publicação, sendo assegurada, em permanência, pela equipa de editores, mas também pelo talento de muitos criadores. $\mathrm{O}$ que, por outro lado, tem permitido dar a conhecer as obras de muitos dos nossos poetas, músicos, pintores e outros artistas. Citando Ariana Cosme, colaboradora permanente e membro do Conselho Editorial, «na PÁGINA está a nossa pegada e a de tantos outros, como uma constelação de olhares plurais e democráticos, podendo desta forma perdurar num tempo de realidades voláteis» (2016, edição n. ${ }^{2}$ 208, p. 9).

De salientar ainda que todas as edições incluem entrevistas a personalidades de referência, muitas delas feitas em registo de homenagem e reconhecimento. Por 


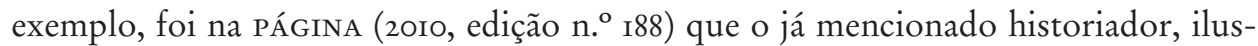
tre pedagogo e ativista político, Rogério Fernandes, deu o seu último testemunho público, poucos dias antes de falecer. Como confessava Américo Peres, um dos mais antigos colaboradores e membro do Conselho Editorial em entrevista concedida no momento da sua aposentação como docente da Universidade de Trás-os-Montes e Alto Douro, «é bom ser-se reconhecido como alguém que luta pela coesão social, por melhor educação, por melhor justiça, por melhores condições de vida das pessoas» (20I4, edição n. ${ }^{\circ}$ 204, pp. 49-5I).

Em suma, aliando os princípios do conhecimento aos valores do reconhecimento, a PÁGINA tem procurado abordar temáticas atuais e diversificados, seja através das imagens, dos artigos, das entrevistas ou das reportagens. Por esta razão, é dada especial atenção aos temas da paz, da justiça, da pobreza e da exclusão social. Como notou Ricardo Vieira (20I6, edição n. ${ }^{\circ}$ 208, pp. 22-3I), «o mundo visto a partir da escola é muito pequenino, de vistas curtas». Por outro lado, parafraseando José António Caride (20I9, edição n. ${ }^{\circ}$ I3, p. II), a escola não pode ser só escola e as aprendizagens não podem ser só curriculares, pelo que a consciencialização dos professores para as questões sociais constitui um dos elementos fundamentais da sua da ética profissional, enquanto ética cívica e pública. No seguimento destas preocupações, a PÁGINA inclui, desde há muito, uma rubrica explicitamente dedicada à Pedagogia Social, cumprindo assim um papel pioneiro em termos de divulgação desta área educacional no nosso país.

São todas estas características que, em conjunto, justificam a forma como a PÁGINA é estimada, avaliada e reconhecida, tanto no plano nacional como internacional. Insere-se neste âmbito, e como foi já referido, a presença no III Congreso sobre Prensa Pedagógica, da Universidade de Salamanca, realizado em outubro de 20I8. Sendo ainda de destacar, a título de exemplo, que a revista tenha sido convidada a participar num dos eventos mais importantes do mundo editorial, na Feira Internacional do Livro de Guadalajara, México, em 2016.

No momento em que damos este testemunho sobre o passado, o presente e o futuro da PÁGINA, sai a público a edição n. ${ }^{\circ} 2015$, produzida em circunstâncias particularmente difíceis, motivadas pela epidemia que abalou o mundo neste ano inesquecível e atípico. Não podendo ficar alheia às interpelações de um tempo como este, a PÁGINA propôs-se refletir sobre os desafios do futuro, tentando perspetiva-los para além do imediato e da contingência. Se, por um lado, se reconhece que ainda é cedo para produzir avaliações ou projeções sustentadas sobre uma experiência coletiva tão disruptiva e perturbadora, por outro, não podemos ignorar os seus efeitos devastadores, em especial junto das pessoas e dos grupos humanos mais vulneráveis (Baptista, 2020, editorial, edição n. ${ }^{\circ}$ 20I5).

Este desafio foi aceite, de forma extraordinária, por todo quantos colaboraram nesta edição, entre os quais destacamos o conjunto de alunos, educadores e outros membros das comunidades educativas que aceitaram dar o seu contributo reflexivo. Recorrendo a palavras de Domingos Fernandes (2020, edição n. ${ }^{\circ} 2$ I5, pp. IO-I3), em entrevista conduzida por António Baldaia, jornalista e editor, os desafios da educação num contexto de cidadania pós-covid obrigam a ir ao fundo das questões e dos problemas, organizacionais, profissionais e pedagógicos. $\mathrm{Ou}$, como assinala outro colaborador, José Luís Gonçalves, «em tempos de pandemia, o vínculo social precisa urgentemente de ser regenerado através de iniciativas revitalizadoras da confiança 
mútua, promotoras de encontros humanos que despoletem trocas aos mais diversos níveis: informativo, afetivo, de competências e de solidariedade (2020, edição n. ${ }^{\circ} 215$, p. 45). É, portanto, nesta lógica de revitalizado e regeneração, neste dar e receber confiança, que nos situamos.

\section{Considerações finais}

Como foi sendo dito, a PÁGINA inscreve-se na melhor tradição da imprensa pedagógica, ocupando um lugar incontornável no espaço público de comunicação que designa por «Praça da República», de acordo com o seu compromisso fundamental com a construção crítica e amplamente partilhada de uma cidadania sensível, reflexiva e solidária. No seguimento deste compromisso, pretendemos prosseguir, ampliando e reforçando os laços com os nossos colaboradores e leitores, no quadro de uma relação rigorosa e transparente, autónoma do poder político e independente de todos os poderes particulares.

Determinados a caminhar neste sentido, contrariando a cultura do medo, da desconfiança e da indiferença, optamos pelo caminho exigente da utopia, aqui valorizada em toda a sua função mobilizadora e crítica, como dinâmica de transformação em curso, «na tentativa de dar à Democracia todo o seu virtuosismo e toda a força que pode comportar, anulando o que de sinistro e aberrante pode ser gerado a partir dela», prosseguiremos, teimosamente, mesmo que os ventos e as marés sejam desfavoráveis, como se dizia no editorial da edição n. ${ }^{\circ} 212$ (2018), assinado por Ana Brito Jorge.

Movida por estas preocupações e impulsionada pela força de um trabalho rigoroso e desejavelmente partilhado, a PÁGINA continuará, certamente, a posicionar-se do lado mais fecundo, mais criativo, mais informado e mais transformador do tempo. Mantendo-se, desta forma como um projeto editorial aberto à disseminação reflexiva do conhecimento sobre as diferentes dimensões da educação e da vida em sociedade, numa perspetiva de permanente reinvenção e aprofundamento dos valores da liberdade, cidadania e da democracia.

\section{Referências}

Afonso, A. J. (20I2). Fragmentos de Escrita Pública. Coleção a Página (3). Porto: Profedições. A PÁgina da Educação. (20I0), n. ${ }^{\circ}$ I88. Porto: Profedições.

A PÁgina da Educação. (20I5). Estatuto Editorial (www.apagina.pt).

A PÁgina da Educação. (20I7), n. ${ }^{\circ}$ 209. Porto: Profedições.

Baptista, I. (2005). Dar rosto ao futuro. A educação como compromisso ético. Porto: Profedições.

Baptista, I. (20I4). A Página da Educação, n. ${ }^{\circ}$ 203. Porto: Profedições.

Baptista, I. (2020). A Página da Educação, n. ${ }^{\circ}$ 215. Porto: Profedições.

Bento, G. (1978). O Movimento Sindical dos Professores. Lisboa: Editorial Caminho.

Breyner, S. M. (2015). Obra Completa. Porto: Assírio \& Alvim.

Brito Jorge, A. (20I2). A Página da Educação, n. ${ }^{\circ}$ 212. Porto: Profedições

Caride, J. A. (2019). A Página da Educação, nº 213 . Porto: Profedições.

Couto, M. (2013). A Página da Educação, n. ${ }^{\circ}$ 202. Porto: Profedições.

Cosme, A. (2016). A Página da Educação, n. ${ }^{\circ}$ 208. Porto: Profedições. 
Fernandes, D. (2020). A Página da educação, n. ${ }^{\circ}$ 215. Porto: Profedições.

Fernandes, R. (2008). O Tempo da Escola. Porto: Profedições/Jornal a Página.

Gonçalves, J. L. (2020). A Página da Educação, n. ${ }^{\circ}$ 215. Porto: Profedições.

Hernández Díaz, J. M. (20Io). A Página da Educação, n. ${ }^{\circ}$ I9I. Porto: Profedições.

Lopes, J. T. (2017). A Página da Educação, n. ${ }^{\circ}$ 191. Porto: Profedições.

MendonçA, M. (20I6). In Educação e Sindicalismo Docente. SPN. Porto: Profedições.

Nóvoa, A. (2009). A Página da Educação, n. ${ }^{\circ}$ I86. Porto: Profedições.

Rodrigues, D. (2015). Equidade e Educação Inclusiva. Coleção a Página (I). Porto: Profedições.

Peres, A. (20I4). A Página da Educação, n. ${ }^{\circ}$ 204. Porto: Profedições.

Santos Guerra, M. A. (201i). El Árbol de la Democracia. Coleção a Página (2). Porto: Profedições.

Serralheiro, J. P. (20II). Reinventar os Sistemas Educativos. Coleção a Página (I). Porto: Profedições.

Vieira, R. (20I6). A Página da Educação, n. ${ }^{2}$ 208. Porto: Profedições. 